\section{Briginal anticlew.}

THE TREATMENT OF ELBOW-JOIN'T FRACTURES IN THE POSITION OF ACUTE FLEXION, WITHOU'T SPLIN'TS; WITH REPORT OF CASES. ${ }^{1}$

BY H. L. SMITH, M.D.

Assistant Visiting Surgeon, Boston City Hospital.

The treatment of elbow-joint injuries with the forearm in acute flexion is not new. For the most part, this position has been employed hitherto in sporadic cases to meet special conditions. The most common reason for such treatment is the fact that by this means it is possible to prevent a fragment of bone, or the loosened head of the radius, from slipping into the angle in front of the point, where it would prevent full flexion.

A few surgeons have preferred to put up all fractures of the lower end of the humerus at a point within the right angle. Mr. Thomas, of Liverpool, treated all such cases without splints, simply fasteuing the hand well up to the neck by means of a halter attached to the wrist; and it appears from a recent discussion on the subject, reported in the British Medical Journal, that his successor, Mr. Robert Jones, coutinues the practice. Professor Markoe, of New York, is reported by Hamilton as advocating flexion to a few degrees less than a right angle, and Dr. Dulles, of Philadelphia, has been led, on purely theoretical grounds, to suggest the same treatment. So far as the writer has been able to learn these surgeons stand alone in this practice.

It may be said at once that acute flexion at the elbowjoint, as employed or advocated hitherto, except per. haps in the case of Dr. Dulles, is entirely different in priuciple and degree, from that upon which this paper is based.

From a series of experimental fractures of the elbowjoint, undertaken for the purpose of finding at what angle the fragments could best be held in position, and reported in January, 1894, the writer became fully convinced, although in the beginning no such conclusions had been anticipated, that if it were possible, with safety to the patient, to hold the forearm at a point of full, almost forced, flexion, the fragments, once brought into correct position, would remain fixed. More than this, it appeared that the variety of fracture, the direction of the lines of cleavage, and the degree of comminution seemed not to make the slightest difference in the result.

It was almost incredible that so sweeping a statement would prove rigidly true, and the fact was accepted only after the ground had been gone over again and again, and with constant results. So far as any purely experimental work could be said to prove anything, the conclusion seemed justified that after fractures of either condyle, of whatsoever magnitude, after transverse fractures, including epiphyseal separations, after 'T-fractures, or other comminuted fractures, if the fragments are once replaced, and the forearm completely flexed, no mobility can be detected and it is almost an impossibility to reproduce the deformity. In no other position of the forearm is this true, even to a small degree. As long as the coronoid process remains intact, and either the triceps tendon or the

1 Read before the Surgical Section of the Sufrolk District Medica Society, April 3, 1895. posterior ligament retains its conuection with the olecranon process, the locking has always proved solid.

It will thus be seen at ouce that the term "acute flexion," as used in this paper, means something entirely different from the same expression as employed in the past. It contemplates a flexion of the forearm carried to its limit and applied to every variety of fracture involving the joint region, save only that of the olecranon process.

Can this extreme flexion be employed with safety in a limb whose soft parts are severely lacerated, and the seat of extravasation and effusion, more especially as in addition, there is involved a joint whose capsule speedily becomes distended? And even if the arm itself be not imperilled, can such a tense position be tolerated by the patient?

The cases first treated were watched with great care and some misgiving but no untoward symptom developed, and so far as the writer knows nothing has occurred in any subsequent case to require a change of treatment, either from embarrassment of the circulation or discomfort caused the patient.

A sufficient reason for this immunity appears at once when we consider that in an arm having au average amount of fatty tissue it is found impossible to flex the forearm far enough to stop the radial pulse, the coronoid process bringing up against the humerus when the forearm makes with the upper arm an angle of about $35^{\circ}$, thus giving ample space for the vessels to change their direction without being too sharply bent on themselves or compressed by the soft parts. Unless, then, there are bony fragments so displaced as to press directly upon the vessels, the danger of strangulation is slight, since the extravasated blood and serum is quickly driven from the tissues by the pressure.

The appearance of an elbow that has been treated in acute flexion for several days is instructive. The smooth tense swelling, by this time much pigmented, is present on the posterior aud lateral aspects of the joint, whereas, if the forearm be slightly extended, so as to expose the anterior surface, one sees almost no trace of swelling or discoloration, both these ending in a sharply defined live, on each side, at the point where pressure began. One would say that a similar pressure on every part of the joint, if such were possible, would be of material aid in hastening repair.

From the foregoing considerations, therefore, as well as from the collected experience of cases successfully treated during the past two years, it would appear that acute flexion of the elbow can be employed with safety. Is it irksome to the patient? During the first twenty-four hours there is some discomfort, but what proportion of this is a necessary part of the in. jury or would follow the application of any sort of restraint whatever, and what part is to be attributed to the acuteness of position it is not easy to say. In no case, however, have I known it to be so great as to call for a change of position. Of downright pain, or even of prolonged discomfort, there need be none. In fact it is generally sufficient to make rather moderate pressure, in a fresh accident, and to increase the flexion as the swelling disappears. Indeed, but for the desirability of making the reduction under anesthesia, at the time the examination and diagnosis is made, it would seem good practice to leave the arm without dressing of any kind for several days, during which interrupted bandaging might be applied, and to bring 
the parts into position and hold them by flexing the arm only when the swelling had partially disappeared. In looking over the records at the Boston City Hospital, I have learned of a method employed by Dr. Post which seems a happy solution of this difficulty. The patient is not etherized immediately on entrance, but after a careful examination, some temporary dressing is applied, usually with the elbow at a right angle. At the end of from three to six days ether is given, the diagnosis confirmed or corrected, as can now be done with much greater ease and certainty, the fragments carefully molded into place, and the permanent treatment, with acute flexion, entered upon.

In reporting the experiments alluded to above a few cases were given to show the safety of the method. Since that time the plan has been employed in the practice of several surgeons, and the cases at the City Hospital now number in all wore than thirty. Of these $I$ have been able to find and take careful meas. urements of twenty: So far as can be learned from the records all the remaining cases were equally satisfactory.

In studying the results obtained two elements demand consideration. Perfect repair supposes not only restoration of function but restoration of form, that is, total absence of deformity. While deformity is often associated with loss of function it is not necessarily so. For practical purposes we may consider the function of the elbow to be identical with its mobility. A perfect result, then, so far as usefulness is concerned, would be the restoration of normal flexion and extension. But uninjured arms often vary not a little in the arc of motion at the elbow, and yet one is as useful as the other. The degree of stiffuess which can exist without crippling its possessor is quite remarkable. From a series of seventy-five fractured elbows, recently studied, it was concluded that a motion of from ten to twenty degrees on each side of the right angle would yield an arm so useful that the wage-earning power of the average individual need hardly be diminished a particle. It is only in certain special kinds of skilled labor that more motion is required.

On the question of deformity much has been written during the past few years, especially in this country. Most attention has been given the so-called "gunstock" arm, sometimes called cubitus varus, and caused by a reversal of the usual humero-ulnar angle.

The weight that has been attached to this subject, and the influence it has had upon methods of treatment is quite surprising. With little or no study of the size of this angle as met with in normal arms, or of its utility and the importance, therefore, of preserving it, the "gun-stock" deformity having been considered to be due to the ordinary methods of dressing the injuries under discussion, not a few surgeons have been led, on this ground alone, it would seem, to employ and advocate a method of treatment which places the forearm, during the first weeks of repair, in the position of full exteusion. The explanation of the mechanism of this deformity has thus far been largely a matter of theory, and it is the belief of the writer that the views usually held hitherto will not bear close inspection. In a paper soon to be pubished, this matter will be spoken of more at length, and it need only be said here that the importance of preserving the so-called carrying-angle, has, in the opinion of the writer, been very much exaggerated. If there were other reasons for employing the position of extension they would call for careful consideration before being disregarded, but when, as is the fact, that position is deliberately chosen merely because it allows the humero-ulnar angle to be made equal to that of the other arm, we are justified in concluding that the loss of this angle must be considered a very serious matter, since, to preserve it we are advised to run the risk of an arm permanently extended. Let us see what conclusions are reached from a study of the angle in normal individuals. As a matter of fact the arms are almost never alike in this respect, the difference in the angle on the two sides being sometimes as much as 10 or 15 degrees. In different people the greatest variation is found, the size of the angle varying from $-5^{\circ}$ to $+30^{\circ}$, and curiously enough, the owners of the arms with little or no angle or even with one reversed never know the lack. Moreover, the reversed angle that follows injury does not cripple the individual, usually, in any of the wageearning functions. In so far as the reversed angle indicates that the fragments are not in exact position it is worth consideration, for it may lead to a greater care in treatment, but neither from the standpoint of deformity or disability can it alone serve as a sufficient reason for a complete change of treatment. ${ }^{2}$

The twenty cases of this series will not be given in detail, but the results tabulated and the averages compared with those obtained from the series of seventyfive already alluded to, and, in some particulars, with the averages found in normal arms. For convenience the present series will be called Series $A$; that of the 75 cases Series B; and the normal cases Series C. The method of taking averages is not entirely satisfactory, but is far superior to mere general statements.

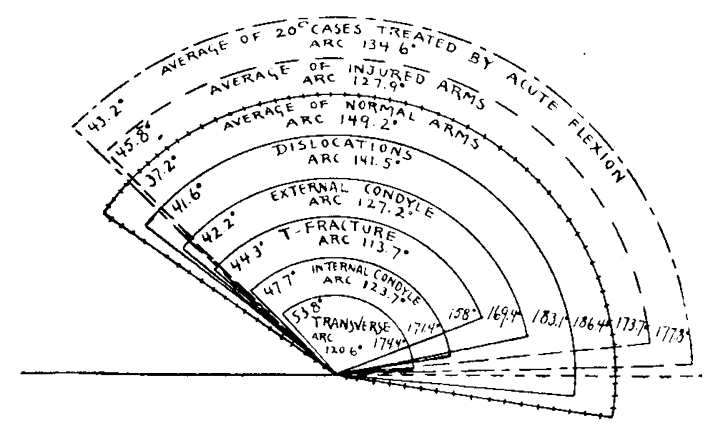

VARIETIEs. - Ten of these cases were fractures of the external condyle, while there were only three of the internal condyle. Two were transverse fractures, and five T-fractures. There were thus severeases of the severe type, from which it appears, as shown previously by a study of Series B, that almost all cases of gun-stock deformity arise. In that series the transverse and $T$-fractures made $40^{\circ}$ of the whole. Here we have them in a proportion of 35 per cent., so that a comparison in respect to the angle will be fair.

AGE. - The average age in all cases is nine years; in Series B it was eleven years. It was considered as probably more than mere chance that the average age of those whose external condyle was broken, in Class

2 In making this statement the writer does not wish to underrate the importance of avoiding, by every pıoper means, not only this but every other deformity. In lact, as will appear in he discussion of results, one of thestrong reasons for the adoption of acute flexion is the fact that when it is employed in the manner here advised there is almost no tendency whatever toward the formation of the reversed angle. It would not be considered proper, however, to urge a change from ordinary methods to acute flexion if that preservation of the angle were its sole merit. 
$B$, was only about half that of those having fractures of the internal condyle, the figures being eight and fifteen years respectively. It is worth noting that in the present series the same difference is noted, the tigures being 5.6 years and 14.6 years. It was then suggested, in view of the fact that the elbow angle is known to increase as a child grows, at least in some cases, that the impact which causes the fracture may be directed, in the younger child, more exactly in the line of the arm, and thus cause fracture of the external condyle, or, if greater damage is done, a T-fracture, while in the older one, the angle being greater, the force is directed farther inward toward the internal condyle.

Extension. - Eight, or 40 per cent., gained an extension equal to or greater than that of the other arm; in Class B this was 46 per cent. The average amount of increase, however, was greater in Series $A$ $\left(8.7^{\circ}\right.$ as compared with $\left.8.2^{\circ}\right)$. The real test as to motion restored is found in the average number of degrees of extension lost. In Series $\mathbf{A}$ it is $8.2^{\circ}$; in Series $B, 12.7^{\circ}$. We have made, then, a clear gain of $4.5^{\circ}$ in this particular.

Flexion. - Nine cases, or 45 per cent., lost nothing in flexion. In Series B it was 40 per cent. Just 50 per cent in Series A and 46.6 per cent. in Series B had flexion as good or better than before. The total average loss in flexion in this series is $6^{\circ}$, while in Series B it was $8.6^{\circ}$.

To illustrate more clearly: The average normal arc of motion in the arm lies between $37^{\circ}$ and $186^{\circ}$. In the 75 cases of Series $B$ this arc was cut off $12.7^{\circ}$ in extension and $8.6^{\circ}$ in flexion, thus decreasing the arc by $21^{\circ}$. In the present series this figure is $14^{\circ}$, instead of $21^{\circ}-$ but two-thirds as much. This gain in arc of motion is well shown in the diagram.

Carrying Angla. - Series A, uncbanged 40 per cent., Series B, 10 per cent. The diminution in angle is the most important item, as ft is this which causes the internal angle. In this series of cases treated by acute flexion only 30 per cent. show any decrease, whereas in Series B there are 70.6 per cent. The average tendency, in all cases, toward the formation of an internal augle is, in Series A $0.8^{\circ}$, while in the former series it was $7^{\circ}$. That is, there is nine times as great a tendency to the formation of an internal angle after the ordinary methods of treatment as after treatment by acute flexion.

But it has already been intimated that the two arms on the same side rarely correspond in angle. In fifty cases (Series C) it was found that the tendency of one arm over its fellow to form an internal angle is just $1^{\circ}$. It would thus appear that the acute position, which gave a corresponding figure of $0.8^{\circ}$, prevents all tendency in the fragments to slip in such a way as to bring about the internal angle.

Thickness. - Several series of measurements were taken about the joints, but the only one that need be given, since it may be taken in general as an index of the bony changes, is that of the distance between the condyles. In normal cases this distance is not the same on the two sides of the body, the average difference in the 50 cases of Series $C$ being 3.1 millimetres. In Series $B$ the average increase is 5.5 millimetres; in Series $A$ it is 4 millimetres.

Two or three cases, especially of T-fractures, have shown considerable thickening. It has usually been found that these were put up by simply flexing the arm, with no special effort to mold the fragments into place. Obviously this precaution is called for in all cases where there is opportunity for blood and serum to separate fragments. It appeared, from the experiments, that the best reposition was gained if, while the arm was being flexed, the internal condyle was pushed forcibly downward and backward and the joint compressed laterally. The latter manœuvre also prevents that inward rotation of the lower fragment on its antero-posterior axis, in the case of the transverse fracture, which seems to be the real cause of the gunstock deformity.
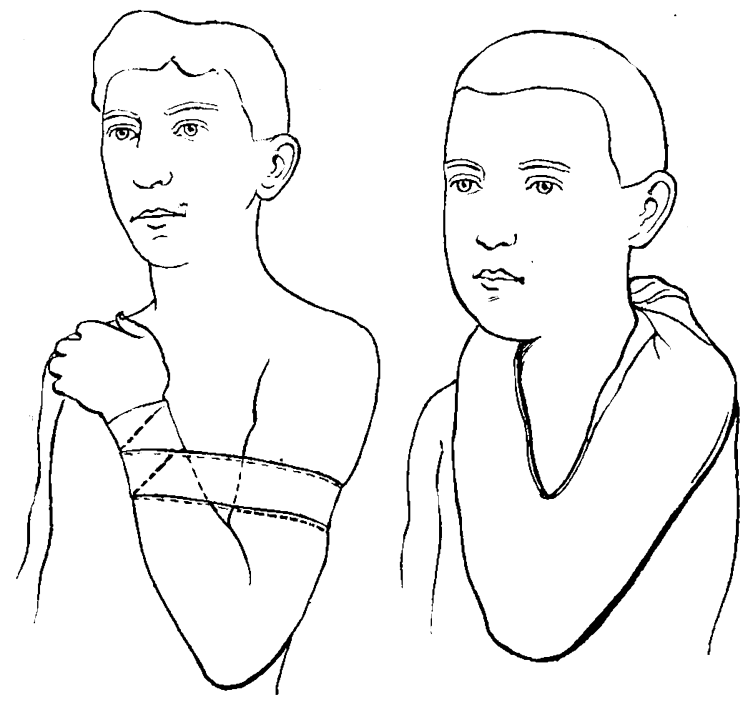

Not having at hand any splint that would retain the arm in the acute position desired, the writer employed, in the first cases, a broad ribbon of adhesive plaster, applied as a double figure-of-8, near the wrist and as high as possible on the arm. The whole arm was then supported loosely in a sling or was suspended from the neck by means of a bandage fastened to the wrist. This form of dressing is so simple and yet firm and comfortable, and the whole elbow region is left so perfectly free from pressure and open for inspection, that all more complicated forms of apparatus and splints which have been devised and given a tria! from time to time have now been discarded in its favor. The very principle, deduced by the experimental fractures, upon which this treatment is based, renders any form of splint unnecessary and indeed an injury. As long as acute flexion is maintained, the fragments being in position, the interlocking bones act upon each other mutually as the very best form of splint, so that any apparatus which holds the forearm flexed fills every requirement. The comfort to the surgeon of being able to dispense with all apparatus hitherto used need only be hinted at.

An exceedingly neat and comfortable dressing, has been evoked in the service of Dr. A. Post in the 
children's ward at the Boston City Hospital. A sleeve, made at the acute angle desired, is fitted to the arm, one side being stitched up after it is applied, the ends of the sleeve extending far enough to be tied behind the neck as a support. The results after its use have been entirely satisfactory.

No positive rule has been followed as to the length of time during which the acute flexion is maintained. Usually the forearm has been extended by degrees, beginning, according to the case, from the third to the fifth week, until it has reached a right angle, where it is allowed to rest in a sling. In some instances a rightangled splint has been worn for a week or more, but the writer has come more and more to believe that quite as good and rapid results are obtained if no motion whatever and no change in position is permitted for at least four and perhaps five or even six weeks. This is a question on which there is still the widest variance of opinion, and careful study of this point is urgently called for, since there seems no good reason why positive conclusions may not be reached.

'To sum up briefly: From the evidence of experimental fractures, and results of clinical experience the writer believes the following propositions justified.

(1) All fractures of the lower end of the humerus, once in position, are held in place if the forearm is kept acutely flexed.

(2) Such flexion can be used without danger to the limb or undue distress to the patient.

(3) The only force required being one of flexion, no rigid apparatus is needed, it being sufficient to strap the forearm to the arm. One of the strong points of this treatment, therefore, is its perfect simplicity.

(4) The only points to emphasize are: Be sure to replace fragments as flexion is made, taking great care that the internal condyle is as low as possible and the joint not widened by effusion between fragments. If the condyle is kept down no gun-stock deformity can occur.

(5) In the cases thus far treated the amount of motion gained has been slightly greater than after ordinary methods. The amount of deformity has been very much less.

\section{ASEPTIC MIDWIFERY AMONG THE VERY POOR. 1}

BY C. D. YOUNG, M.D. (HARV.), ROCHESTER, N. Y.

THE subject $I$ have chosen for your consideration this evening is, I am well aware, one that is commonplace, and yet I venture to make it the theme of my essay, for the reason that puerperal sepsis is not an unknown thing in this fair city. The operating gynecologist knows it, whether the practising obstetrician does or not. As Reynolds has well said: "Those who are in the habit of believing that the slight disturbances of health and temperature, which either constitute mild sepsis or herald the approach of grave sepsis, are due to milk fever, nervousness, excitement and other indefinite ailments, do not understand that, under strict asepsis, the convalescence from labor is always perfectly smootb and unattended by any elevation of temperature unless some definite entity of intercurrent disease is present."

Taking it for granted then, that puerperal sepsis does occur, even, at times, in the practice of the best

1 Read before the Rochester Pathological Society, March 28, 1895. physicians, a narration of personal experience may prove the starting-point for profitable discussion.

First, however, let me briefly review the history of aseptic midwifery. It was in 1843 that Dr. Oliver Weudell Holmes began his crusade against filth in the lying-in chamber. It was a hard and well-fought battle and the laurels he then won will remain green as long as any with which the literary world has crowned the Autocrat.

And the need of this fight was only too evident. The great Dublin Hospital was at one time threatened with closure by law, owing to the high mortality among its lying-in patients. A recent report of the Lying-in Department of the New England Hospital shows that, between 1862 and 1872 , one out of every 50 cases treated died of sepsis. Since 1884, and up to the date of the report, 897 cases were treated without a death. In 1890, the Out-patient Department of the Boston Lying-in Hospital, where patients are cared for in their own homes by students of the Harvard Medical School, was able to record 1,000 consecutive cases without a death from any cause. In 1893 , in this clinic, 1,352 cases were thus treated with but 15 cases of sepsis and but one death - that of a patient who refused appropriate treatment. From personal knowledge, I can testify that these cases are cared-for in the most filthy tenements of Boston. It is due to the experience and instruction gained at this clinic, that I can report my cases to-uight with so small a percentage of preventable sepsis.

In the New York Maternity, Blackwell's Island, during the year from October 1, 1882, to October 1, 1883, the death-rate from sepsis was 6.06 per cent. and during the last month of that year, it reached 15.69 per cent. of all women confined there. Then Dr. Garrigues introduced the antiseptic system and in the following year, had a death-rate of but .0059 per cent. and in the year 1884-5, he still further reduced the rate to .0018 per cent. The introduction of antiseptic measures in the Boston Lying-in Hospital, enabled Dr. W. L. Richardson to reduce a death-rate from sepsis, of 4.58 per cent., in $1883-4$, to .000 in $1886-7$.

These figures ought to be conclusive as to the necessity of combating sepsis both in hospital and private practice.

And now as to the technique. It is so simple and involves so little preparation that it can easily be carried out amid the most adverse surroundinge. All that is essential is comprised in this list: a box of aseptic vaseline, a piece of soap, a small bottle of carbolic acid, a few tablets for preparing the solutions of bichloride of mercury, a nail-brush, plenty of hot water, a small dish for the carbolic solution and a large one for the bichloride, a fountain syringe, and clean towels or cloths. A non-essential that, in this city, might almost be classed as an essential, is the district uurse. She may be obtained, at any hour, by application at the City Hospital. In all my cases, she has proved a most welcome and efficient aid in the conduct of labor in the slums.

Personal cleanliness is, of course, of prime importauce. The obstetrician's habits should include frequent bathing and a frequent change of clothing. $\mathrm{He}$ should never be in the condition of him to whom Charles Lamb once said, "If dirt were trumps, you would hold a full hand."

It is my habit to advise patients to send for me as 